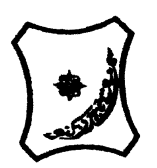

Bayero Journal of Pure and Applied Sciences, 10(1): 462 - 467

ISSN $2006-6996$

\title{
A COMPREHENSIVE MAPPING OF MALARIAL INFECTIONS IN CHILDREN UNDER 10 YEARS IN KANO CENTRAL SENATORIAL DISTRICT, KANO STATE, NORTHERN NIGERIA
}

\author{
Farouk, S. Nas
}

Biological Sciences Department, Bayero University, Kano, Kano State, Nigeria Corresponding author: fanasg6g7@hoo.com

ABSTRACT

This study is a baseline to assess and map out the distribution of malaria infection using the prevalence level within the central senatorial districts of Kano State, Northern Nigeria. Blood samples were collected from 50 individuals' aged below 0 - 10 years from which each of the 15 LGA. Thick and thin blood films were prepared and stained with Giemsa following standard procedure and examined for malaria parasites species identification. The overall prevalence of malaria was $40 \%$ and was caused by Plasmodium falciparum. Mapping of malaria using prevalence data showed level of endemicity that ranged from meso to hyper endemicity with a larger proportion of the LGAs (40.6\%) being meso-endemic. In conclusion, targeted mass treatments of infections including asymptomatic ones are recommended as promising measures to reduce malaria surge.

Key words: Mapping, malaria distribution in children under 10 years, $P$. falciparum, Kano State

\section{INTRODUCTION}

According to researchs in Nigeria, Ghana and Malawi, the implications of inaccuracy in malaria intervention could potentially have a significant impact on clinical and research outcomes. Malaria-specific mortality is difficult to measure correctly, because the disease is most common in areas without the resources necessary to make definitive diagnosis. Mappings suggest more specific identification and categorization of malaria which will improve treatment of patients and monitor the impact of control measures (Ukoli, 1974). Most regulated bodies seeking rapid response in most Roll Back eradication and preventive programmes were frustrated, Lack of comprehensive, coordinated and statistical data on intensity of malaria at that specific suspected area frustrates control programmes(Gilles and Warrel, 1993). Mapping malaria provides a summary of descriptive geographical data on intensity; used in malaria control to support planning, management and decision making. as it makes it easier to visualize some spatial aspects which might not be clearly visible by looking at many pages of available data. Information that can be mapped include: Background information, locations and types of health facilities, population at risk of malaria and location of dump sites. This has long been a concern for epidemiologists. To the knowledge of the author, detailed mapping of malaria endemicity has not been done in Kano State of Nigeria. This has made accurate estimates of the burden of malaria in the state difficult and impossible to rationalize allocation of limited resources for malaria control.

The aim of this report stems from this premise and was set to provide baseline information on the current status of malaria infection and its distribution in the 15 LGAs of Kano State and to generate integrated maps that will be used as reference in any future malaria interventions or research.

\section{MATERIALS AND METHODS}

Ethical Considerations

Ethical approval for this research was obtained from the ethical committees of the Kano State Ministry of Local Government and community services and the Kano State Ministry of Health (Management Board). Informed consent was also obtained from parents and guardians of children prior to sampling.

Pre-survey awareness and reconnaissance visits were made to the Wards chief (Dagaci) and District head (Hakimi) in the study areas to obtain their permission to work in their domain.

Sample determination

The sample size was determined according to Cochran (1999) using the formula: $\mathrm{n}=$ $\left(\mathrm{z}^{2} \mathrm{pq} / \mathrm{d}^{2}\right)$.

Where:

$\mathrm{n}=$ Minimum sample size required (when population is greater than 10,000 ).

$\mathrm{Z}=$ the Standard normal deviation, corresponding to the $95 \%$ confidence level. The value obtain from the normal distribution table $=1.96$. 
Special Conference Edition, November, 2017

$\mathrm{P}=$ prevalence of malaria parasitaemia, $27.29 \%$ was obtained from a previous study in Sokoto. $\mathrm{d}=$ distance between the sample site.

$q=$ complementary probability of $p-=(1-p)$.

A minimum sample size of 48 was obtained and this was rounded up to 50 (i.e. 50 subjects from each of the 15 LGAs).

\section{Sampling Method}

The method used for selection of subjects is the simple random sampling method (SRS), where all frames of the communities are given an equal probability to participate. In each LGA, 5 sampling sites were selected at random.A total of 50 children below 10 years old were randomly selected from each of the 15 LGAs following methods of Jovani et al (2006), while taking into consideration factors which encourages malaria vectors breeding such as proximity to water body, presence of tall trees and grasses, temperature and altitude.

\section{Parasitological Investigation \\ Sample Collection}

For each participating child, axillary temperature was measured using clinical mercury in glass thermometer. Fever was defined as an axillary temperature $\geq 37.5^{\circ} \mathrm{C}$.

Blood samples were collected by pricking disinfected thumbs of the participants using sterile disposable lancets. Thick and thin blood films were stained with Giemsa following standard quality - controlled procedure WHO (2003).

\section{Malaria Mapping}

The coordinates of each sampled areas (LGAs) was obtained by means of a hand global positioning system (GPS) (Garmin 12 mag L version.2.0, Garmin Corporation, USA). The data obtained was converted to an Easting and
Northing, and integrated to an image using Geographic Information System (GIS), (Arc View V3.0 ESERI, CA. USA) to produce a map, which is color-coded in each of the 15 LGAs. Four colour codes, Purple, Red, Pink and White were used to denote four levels of malaria endemicity, holo-endemic (>75\%), hyperendemic $(>50 \%)$, meso - endemic $(11-50 \%)$ and hypo-endemic $(<10 \%)$ respectively WHO (1963).

\section{Data Analysis}

Analysis of Variance (ANOVA SPSS Version16.0): was carried out to test for differences in prevalence rate among age, sex of the subjects studied as well as among the 15 LGA evaluated.

\section{RESULTS}

Malaria Parasite Prevalence

Out of the 750 blood samples examined, 305 were positive for Plasmodium falciparum infection (Table 1), giving an overall prevalence rate of $40.6 \%$. Prevalence rate of the number positive is varied among the LGAs studied,which ranged from $14 \%$ for Kano Munincipal to $70 \%$ for Kumbutso. Madobi and Nassarwa LGAs had 58\% respectively. The present study has shown that majority of the LGAs in Kano Central Senatorial District (10) are meso endemic for malaria infection while the remaining 5 LGAs are hyper-endemic (>50\%) for malaria infection(fig 2). Although no local government area was holoendemic (>75\%), yet none was hypo endermic $(<10 \%)$. This current status of Kano Central Senatorial District with regards to malaria endemicity level is not surprising in view of the large number of water schemes and irrigation projects Main, (1990). Which though essential for its agricultural development constitute breeding sites for the malaria vector.

Table 1: \% Prevalence of Malaria Infection in the 15 LGAs of Kano Central Senatorial district

\begin{tabular}{llccc}
\hline S/No. & LGA & Number of Examined & Number of Positive & $\%$ \\
\hline 1 & Dala & 50 & 19 & 38.00 \\
2 & D/Kudu & 50 & 21 & 42.00 \\
3 & Fagge & 50 & 13 & 26.00 \\
4 & G/Malam & 50 & 27 & 54.00 \\
5 & Gezawa & 50 & 21 & 42.00 \\
6 & Gwale & 50 & 13 & 26.00 \\
7 & Kano Munincipal & 50 & 07 & 14.00 \\
8 & Kumbotso & 50 & 35 & 70.00 \\
9 & Kura & 50 & 23 & 46.00 \\
10 & Madobi & 50 & 29 & 58.00 \\
11 & Minjibir & 50 & 19 & 38.00 \\
12 & Nassarawa & 50 & 29 & 58.00 \\
13 & Tarauni & 50 & 13 & 26.00 \\
14 & Ungogo & 50 & 10 & 20.00 \\
15 & Warawa & 50 & 26 & 52.00 \\
Total & Overall & 750 & 305 & 40.60 \\
\hline
\end{tabular}

A total of 464 male and 286 female were examined, while 190 male and 110 female were found to be positive in Table 2 . 
Special Conference Edition, November, 2017

Table 2: \% Prevalence of Malaria Infection in Relation to Kano Central Senatorial Districts of Kano state.

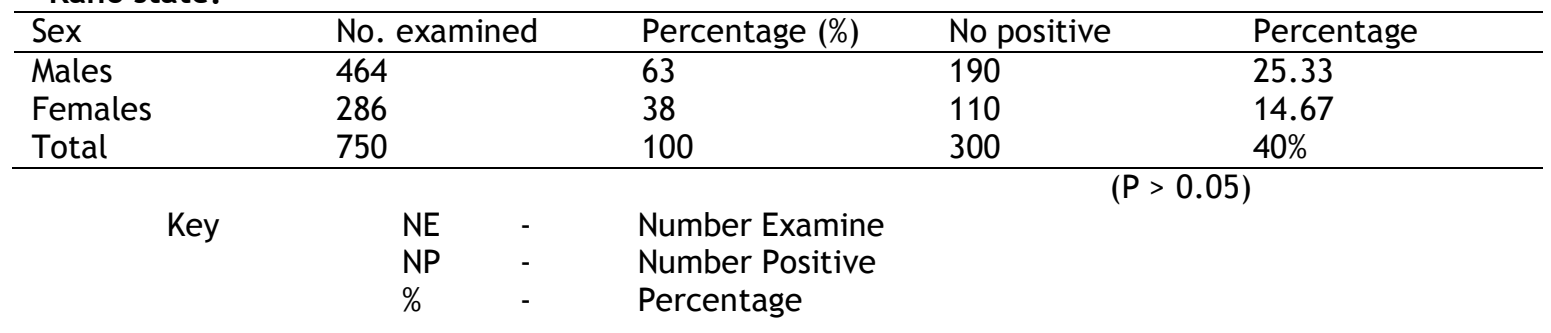

Katsina State

Jigawa State

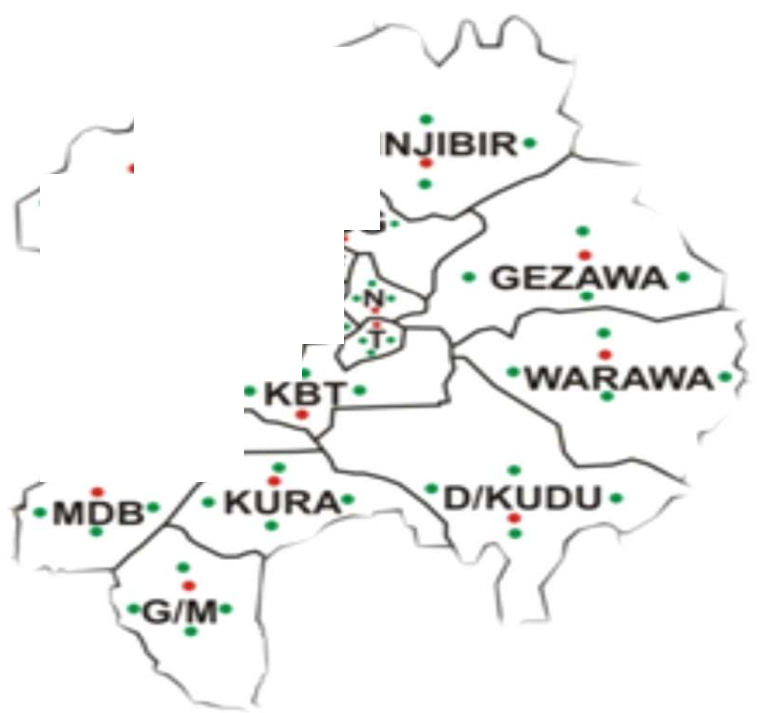

$$
\begin{aligned}
& \text { KEY } \\
& \text { D - DALA } \\
& \text { G-GWALE } \\
& \text { D - DAWAKIN } \\
& \text { T-TARAUNI } \\
& \text { F- FAGGE } \\
& \text { G/M-GARIN MALLAM } \\
& \text { K- KANO MUNICIPAL } \\
& \text { KMB - KUMBOTSO } \\
& \text { MDB - MADOBI } \\
& \text { M-MINJIBIR } \\
& \text { N-NASSARAWA }
\end{aligned}
$$

\section{Malaria Mapping}

A comprehensive mapping of malaria in North Senatorial District of Kano state based on infection in children below 0 - 10 years is shown in Fig 2. The map shows 5 LGAs coded red as hyperendemic with prevalence rates of malaria ranging from 50 to $70 \%$. These include Warawa,
Kumbotso, GarumMallam and Madobi.Majority of the LGAs (10) coded pink are meso-endemic having prevalence rates from 14 to $48.0 \%$. They include Dawakin kudu, Minjibir, Gezawa, Kura, Ungogo, Fagge, Dala, Gwale, Tarauni, and Kano Municipal (KMC). 


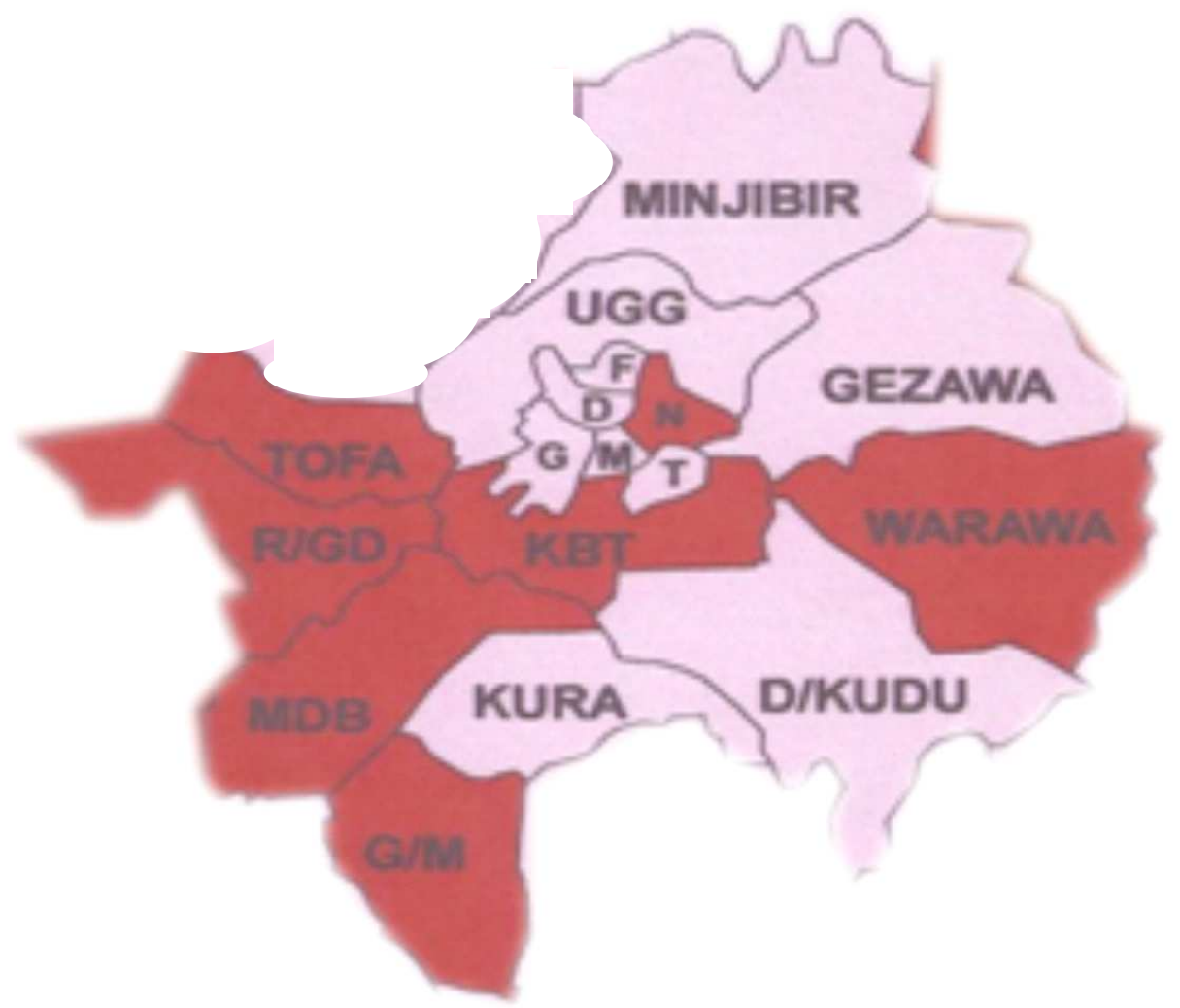

\section{KADUNA STATE}

Key:

\section{Meso Endemic Hyper Endemic}

Figure 2

\section{Map Of Kano Central Senatorial District Showing} The 15 LGAs And The Estimate malaria Endemicity.

\section{BAUCHI STATE}

KEY

D - DALA

G - GWALE

D - DAWAKIN

T - TARAUNI

F-FAGGE

G/M - GARIN MALLAM

K - KANO MUNICIPAL

KMB - KUMBOTSO

$M D B-M A D O B I$

$M-M I N J I B I R$

$\mathrm{N}$ - NASSARAWA

\section{DISCUSSION}

The present study disclosed a fairly high prevalence rate $(40.6 \%)$ of $P$. falciparum infection in children 0 - 10 years of age in Kano central Senatorial districts. This figure is comparable to the $40 \%$ annual prevalence rate reported for Nigeria WHO, (2005a). It however differs from those reported from other parts of the country. It is higher than that of Anumuduet al., (2006) who reported $17 \%$ prevalence rate for eastern Nigeria, lower than that of Umeaneato and Ekejindu(2003) who reported a $46 \%$ prevalence rate for Nnewi Anambra State and even much lower than the 76\% reported by Aribodoret al., (2003) for Abia also in Anambra State. 
Variation of infection rates between local government areas was evident. Attempt to relate this to proximity to water bodies or irrigation projects showed that Kumbotso LGA which recorded the highest prevalence rate of infection (70\%) houses the popular Tamburawa water reservoir bordered by Challawa Gorge dam, Bagauda dam and Challawa water project from river Challawa that support $99 \%$ of the state's needed irrigation water supply. Kumbotsu the largest LGA is characterized by wide land mass rich in tall trees and agricultural activities, congested house arrangements and less water drainages which are features that encourage persistence of the malaria vector. The area also has the popular Coca cola food drink company and Challawa Industrial estate which is a center point for most industries including most of the leather tanneries who create disposal wells that act as reservoirs for breeding malaria vectors thus aiding the spread of malaria in the area. In contrast, Kano Municipal LGA which recorded the lowest prevalence rate of infection $(14 \%)$ has less agricultural activities, less Industries and no big dam or water projects except for the regular gutters and drainages.

The female children in this study were observed to have a slightly higher rate of infection than the male(table 2), although the difference was not significant. Similar studies in adults had indicated higher prevalence rate in males than in females WHO (2006), but there was no scientific evidence to prove the higher prevalence being related to gender as susceptibility to malaria infection is not influenced by gender Gilles and Warrel (2003). This has traditionally been interpreted as a slow buildup of anti-parasite immunity. Therefore as children grow up exposed to repeated infective bites, they acquire an ability to limit the occurrence of high density infections and to reduce the occurrence of fever Plebanski et al., (2000). While other reports suggests that in the first two months of life, children may not contract malaria or the manifestations may be mild with low-grade parasitemia, due to the passive immunity offered by the maternal antibodies Fontenille et al., (1999). Meaning maternal acquired immunity is only protective within very few months after birth, from then onward the child immunity is subjected to the various living conditions that child is exposed to and an

\section{REFERENCES}

Anumudu C.I, Adepoju A, Adeniran M, Adeoye 0 , Kassim A, Oyewole I, and Nwuba RI (2006). Malaria prevalence and ability develop their own immunity as a result of exposure to mosquito bites. The non sterile clinical immunity regulates infection and is usually pronounced in children above 15 years and in adults. These are people who have been exposed to mosquito bites over the years, hence to malaria many more times. Such limited immunity enables the individuals to tolerate severe malaria infection without getting ill even though they may get malaria fever Greenwood et al., (1991).

With regards to the mapping of malaria in Kano Central Senatorial districts, this study has provided data on the prevalence of malaria in children under 10 years generated from the 15 LGAs of Kano Central Senatorial District of Kano State. These data have been presented in a colour coded map (Fig. 2) which reflects the level of malaria endemicity in the different local government areas. Endemicity is a measure of disease prevalence in a particular region and prevalence is the proportion of people infected at a given point in time. Using prevalence data, malaria endemicity has been classified as hypo, meso, hyper and holo endemic following the classification scheme of WHO (1963).

It has been opined that socio-economic development could reduce malaria transmission in a variety of ways. For example, increase in house hold income of guardian and poverty reducing measure in general have the potential to reduce exposure to malaria and to improve health seeking behaviour and quality of treatment Garros et al., (2005).

In conclusion, reinforced health education especially through mass media and targeted mass treatment of infections including asymptomatic ones are recommended as promising measures to reduce $P$. falciparum infection in the state.

\section{Acknowledgement}

The input and advice of the following people are gratefully acknowledged. I remain grateful. The secretary Kano State Ministry for Local Government Area for sending their delegate to inform their subjects on the importance of our research in each of 44 LGA even before our arrival. Mal. Tajuddeen and my research team of BUK Hospital Laboratory and Faculty of Medicine (BUK). Mal. Musa of Central Laboratory (BUK) and Mr. A. Tanwa of Murtala Muhd Hospital's laboratory Kano.

treatment seeking behaviour of young Nigerian adults. Annual. African. Medicine. 15: 82-88. 
Aribodor D.N, Njoku OO, Eneanya $\mathrm{Cl}$ and Onyali I.O (2003). Studies on the prevalence of malaria and management practices of Azia community, in Ihiala L.G.A., Anambra State, SE Nigeria. Nigerian Journal of Parasitology. 24: 33- 38.

Cochran WG (1999). Sampling Techniques. 3rd Ed. John Wiley \& Sons, London, pp. 7282.

Fontenille, D. and Lochouarn, L. (1999). The complexity of the malaria vectoral system in Africa. Parassitologia. 41:267-271.

Garros, C., Weeto, M., Koekemoer, L., Kamau, L., Awolola, T. S., Cotzee, M. and Manguin, S. (2005). Molecular characterization of the African malaria vector Anopheles funestususing RFLPs. [htpp://www.anobase.org/embo_meeti ng/ abstracts/ population I].

Gilles, H.M.Warrell, D.A. (1993). Diagnostic methods in malaria, p.78. Essential malariology, 3d P. Edward Arnold, London, United Kingdom.

Greenwood, B; Marsh, K. and Snow, R. (1991) Why do some children develop severe malaria? Parasitology Today.;7:430440.

Hay, S. Smith, D.L. and Snow, R.W. (2008). Measuring malaria endemicity from intense to interrupted transmission. Lancet Infectious Diseases, 6:369-375.

Hanschield, T. (1999). Diagnose of malaria; a review of alternatives to conventional microscopy. Clin. Lab. Haematol. 21:234-246[pubmed].

Isabella, N. Rumisha, D W, Pilatwe, KRK, Ali, H.I., MokweeTsinyana S. S., Syalla, A. H. and Talla, I.(1995). Six GIS management tools for the control of tropical disease. Application: in Botswana, Senegal and Morocco. Journal Tropical Medicine. 58: 221-227.

Jovani, R. and J. L. Tella (2008). "Parasite prevalence and sample size: misconceptions and Solutions." Trends in Parasitology22: 214-8.

Main, I, (1990) Plasmodium malariae and Plasmodium ovale-the "bashful" malaria parasites. Trends Parasitology. 23:278-283.

Nkuo-Akenji T, Deas J.E, Leke, R.G and Ngu J.L. (1993) Correlation between serum levels of antibodies to the 96KD antigen of $P$. falciparum and protective immunity in Cameroon: A longitudinal study. American Journal of Tropical Medicine and Hygiene.;49:566-573.

Plebanski, M. and Hill, A.V. (2000). The Immunology of Malaria Infection. Current. Opinion. Immunology. 12: 437-441.

Ukoli, F. M. A(1974) Introduction to Parasitology in Tropical in Africa: Parasitic Diseases, Africa-sub saharan Text Flow Limited Ibadan Nigeria pp 406-425.

Ukpai O.M.,Ajoku E.I. (2001). Prevalence of malaria in Okigwe and Owerri areas of Imo state. Nigerian Journal Parasitology. 22(1\& 2): 43-48.

Umeanaeto, P.U. and Ekejindu, I.M. (2006). Prevalence and intensity of malaria in blood donors at NnamdiAzikwe University Teaching Hospital (NAUTH) Nwewi, Anambra State, Nigeria. Nigerian Journal Parasitology. 27: 1115.

WHO (1963) WHO Expert Committee on Malaria. WHO. Tech. Rep. Ser.892;74 pp.

WHO (2003). African Malaria Report, 112pp.

WHO (2005a) Making every mother and child count. World Health Organization (WHO), Geneva. World Health Report.

WHO (2005b). Making every mother and child count. World Health Organization (WHO), Geneva. World Health Report.

WHO (2006). World Health Organization, Geneva. WHO World Malaria Report, 2006. 